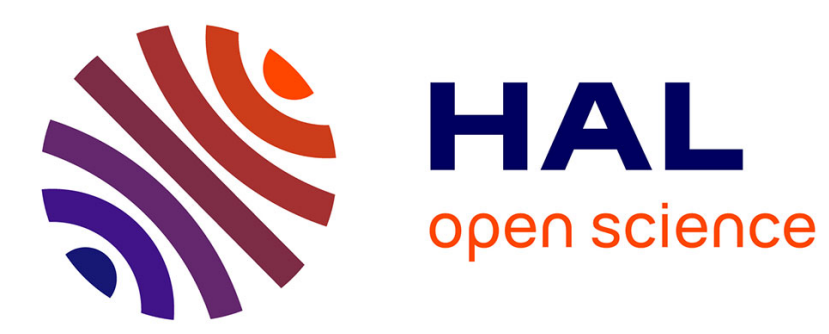

\title{
3D Digitization of Metallic Specular Surfaces using Scanning from Heating Approach
}

Alban Bajard, Olivier Aubreton, Gönen Eren, Pierre Sallamand, Frederic Truchetet

\section{- To cite this version:}

Alban Bajard, Olivier Aubreton, Gönen Eren, Pierre Sallamand, Frederic Truchetet. 3D Digitization of Metallic Specular Surfaces using Scanning from Heating Approach. Electronic Imaging, Jan 2011, San Francisco, France. pp.786413-1, 10.1117/12.872467 . hal-00635539

\section{HAL Id: hal-00635539 \\ https://hal.science/hal-00635539}

Submitted on 25 Oct 2011

HAL is a multi-disciplinary open access archive for the deposit and dissemination of scientific research documents, whether they are published or not. The documents may come from teaching and research institutions in France or abroad, or from public or private research centers.
L'archive ouverte pluridisciplinaire HAL, est destinée au dépôt et à la diffusion de documents scientifiques de niveau recherche, publiés ou non, émanant des établissements d'enseignement et de recherche français ou étrangers, des laboratoires publics ou privés. 


\title{
3D Digitization of Metallic Specular Surfaces using Scanning from Heating Approach
}

\author{
Alban Bajard $^{\mathrm{a}}$, Olivier Aubreton ${ }^{\mathrm{a}}$, Gonen Eren ${ }^{\mathrm{ab}}$, Pierre Sallamand $^{\mathrm{c}}$, Frederic Truchetet ${ }^{\mathrm{a}}$ \\ ${ }^{a}$ Laboratoire Le2i, Université de Bourgogne, 12 rue de la fonderie, 71200 Le Creusot France; \\ babanci University, VPA Laboratory, Orhanli-Tuzla, 34956, Istanbul, Turkey \\ 'Laboratoire LTm, Institut Carnot de Bourgogne, Université de Bourgogne, France
}

\begin{abstract}
Because of the difficulty of dealing with specularity of several surfaces, few methods have been proposed to measure three-dimensional shapes of specular metallic objects. In this paper we present an application on this kind of material of an approach called "Scanning From Heating". This approach has been developed initially for 3D reconstruction of transparent objects. This article presents an application of the working principle of SFH method on material with high thermal conductivity.
\end{abstract}

Keywords: 3D Digitization, 3D Scanning of specular surfaces, Scanning From Heating

\section{INTRODUCTION}

The 3D reconstruction of surface for specular objects is complicated by the fact that light is reflected by the surface following a geometric law without significant diffused component. Therefore no surface features can be observed directly by a camera. Due to specularity of the surface, the classical 3D scanning approach, using laser triangulation method, doesn't give good results. As an example we present on Fig.1 the 3D point cloud obtained using Minolta VI-910 digitizer. We can observe on this result that no 3D point is measured on the specular surface of the fork because no light ray of the laser line of the scanner is diffused toward the camera sensor embedded in the scanner.
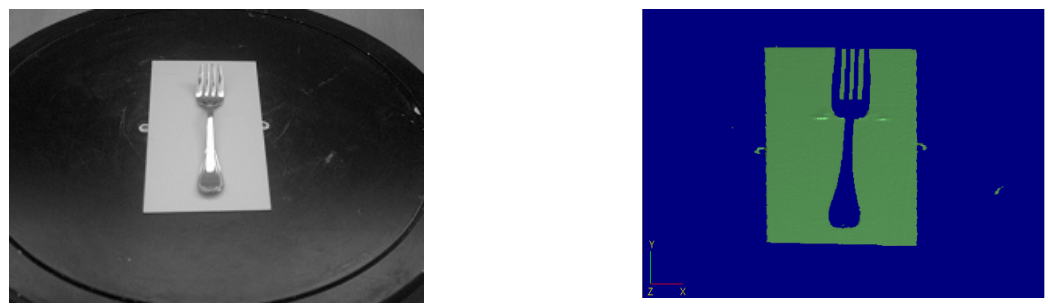

Figure 1: (a) Specular object, (b) 3D Reconstruction by Minolta VI-910 Non Contact 3D Digitizer

However there exist some commercial devices working on specular surfaces. One of the solutions is to consider that the surface is not perfectly specular. The surface is considered as a glossy surface and a little diffuse reflection of a laser ray can be observed with a camera if the distance to the surface is limited. As an example the system, proposed by Kreon [1], uses laser triangulation method to recover 3D surface. Another example is the approach proposed by [2] using chromatic confocal approach. In these two examples, the main limitation is that the distance to the surface can not be superior to 20 centimeters and the field of measurement is less that a few centimeters. That is why these systems need to be placed on a robot arm wich is used to scan the entire object, increasing the 3D reconstruction time.

As classical laser triangulation based method are not able to measure 3D points on specular surfaces, researchers have proposed several approaches dedicated to this kind of surfaces. In [3], Ihrke et al. present a state of the art in transparent and specular object reconstruction and propose a classification of the techniques in four families:

- Shape from Distortion or Deflectometry: these techniques are based on the observation of a known or unknown pattern that is distorted by a single specular surface. [4]

Three-Dimensional Imaging, Interaction, and Measurement, edited by J. Angelo Beraldin, et al.,

Proc. of SPIE-IS\&T Electronic Imaging, SPIE Vol. 7864, 786413 • (c) 2011 SPIE-IS\&T

CCC code: $0277-786 X / 11 / \$ 18 \cdot$ doi: $10.1117 / 12.872467$ 
- Shape from Specularity: these approaches rely on the observation of surface highlights caused by specular reflection at some surface points [5].

- Shape form Polarization: this approach uses the measurement of the polarimetric properties of the light reflected by specular surface. With this measurement, it is possible to obtain a dense field of vectors normal to the surface. The 3D surface is obtained by integrating this field. [6].

- Direct Ray Measurements [7]: to avoid the depth-normal ambiguity in the case of near-field illumination, viewing rays reflected by the specular object can be measured. A calibrated planar target is positioned in different locations with respect to the object and the distorted pattern is observed by a camera. By decoding at least two world positions for every pixel, the reflected viewing ray can be measured.

These approaches give good results but generally needs a perfectly known environment, where all the lighting sources are perfectly controlled. That is why they are not easy to be applied in industrial process. In the following part we will present the Scanning From Heating approach [9]. This method has been initially developed for 3D scanning of glass objects which are transparent and also specular. In section 2 we will present the working principle and its application to metallic materials. Some 3D digitization result result will be presented in section 2.2.3 for simple shapes. Finally conclusion and future works are presented in section 3.

\section{SCANNING FROM HEATING}

\subsection{Scanning From Heating Principle}

All substances continuously emit electromagnetic radiation due to molecular and atomic agitation associated with their internal energy, which is proportional to the material temperature. Emissivity specifies how well a real object radiates energy compared to an ideal body, called a blackbody (a blackbody is considered a perfect absorber and emitter in each direction at every wavelength). The principle of Scanning From Heating is to generate a heated pattern on the surface. According to the Planck's law, this local heated zone creates the emission of an infrared radiation. In the case of dielectric materials, glass for example, the angular emissivity of the material is considered as constant and the emitted radiation can be observed by an infrared camera without distortion due to the orientation of the surface. The experimental setup is presented on Fig.2 (a).
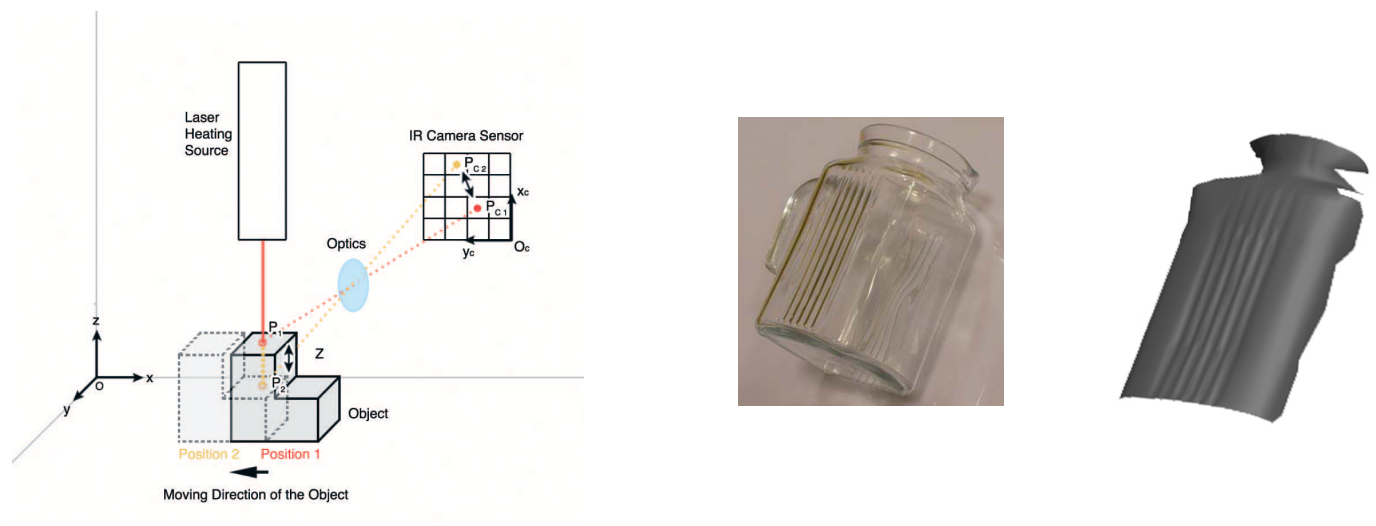

Figure 2: (a) Scanning from Heating principle (b) example of 3D reconstruction of glass

A laser source is used to create a local heating point. An infrared camera is used to observe the IR radiation emitted by the scene. The 2D coordinates of the heated point are computed in the 2D image of the camera. Knowing the parameters of the system (which are obtained by a previous calibration), the 3D coordinates of the point are computed using triangulation method. Some results have been presented in [8] and [9]. On Fig.2 (b) we present results obtained with a glass object where the mean error measurement has been estimated to $360 \mu \mathrm{m}$. 


\subsection{Application to metal}

\subsubsection{Choice of the laser source}

The results obtained on glass objects seem to be interesting. That is why we have tried to experiment this method on other materials. Here we will present an application of SFH method on metallic surfaces. Because of differences of radiative and thermal conduction properties of metals compared to glass, the setup used for glass cannot be exactly the same for metal.

In the case of glass, the absorption spectral domain is superior to $6 \mu \mathrm{m}$. That is why the heating source was a $\mathrm{CO}_{2}$ laser source $(10.6 \mu \mathrm{m})$. As presented in Fig. 3, the absorption coefficient of metals is greater in lower wavelengths. As an example for aluminium, the absorption coefficient is 4 times more important at $1.06 \mu \mathrm{m}$ (wavelength emitted by a NdYag laser) than at $10.6 \mu \mathrm{m}$. That is why we have choosen a near infrared laser source for all the following experiments.

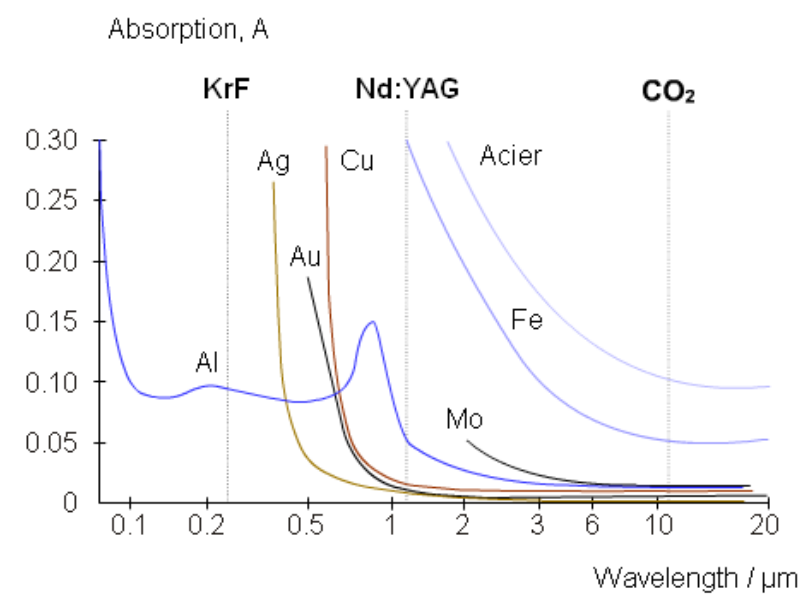

Figure 3: Absorption coefficient for several metals

\subsubsection{Influence of thermal conductivity and choice of the camera}

A second difference between glass and metallic materials is the thermal conductivity. Thermal conductivity of metal is greater than the conductivity of glass: $1.2 \mathrm{~W} /(\mathrm{m} . \mathrm{K})$ for glass, $46 \mathrm{~W} /(\mathrm{m} . \mathrm{K})$ for mild Steel.

In order to illustrate the influence of the conductivity of materials, some simulations have been realized using finite elements analysis software. Some results, for an incident power of $100 \mathrm{~W}$ and an absorption coefficient of 0.5 , have been reported on Fig. 4: (a) for a steel material (AISI 4340 standard) with conductivity of $44.5 \mathrm{~W} /(\mathrm{m} . \mathrm{K}$ ) the temperature variation is about $60^{\circ} \mathrm{C}$ after $800 \mathrm{~ms}$ heating; (b) for the same material with a conductivity of $200 \mathrm{~W} /(\mathrm{m} . \mathrm{K}$ ) (nonexistent material), the temperature variation is about $14^{\circ} \mathrm{C}$ after $800 \mathrm{~ms}$ heating. We can observe that, as the conductivity of the object increases, the maximum variation of the temperature decreases. So it's necessary for these materials to use higher power laser source in order to have a well contrasted spot.
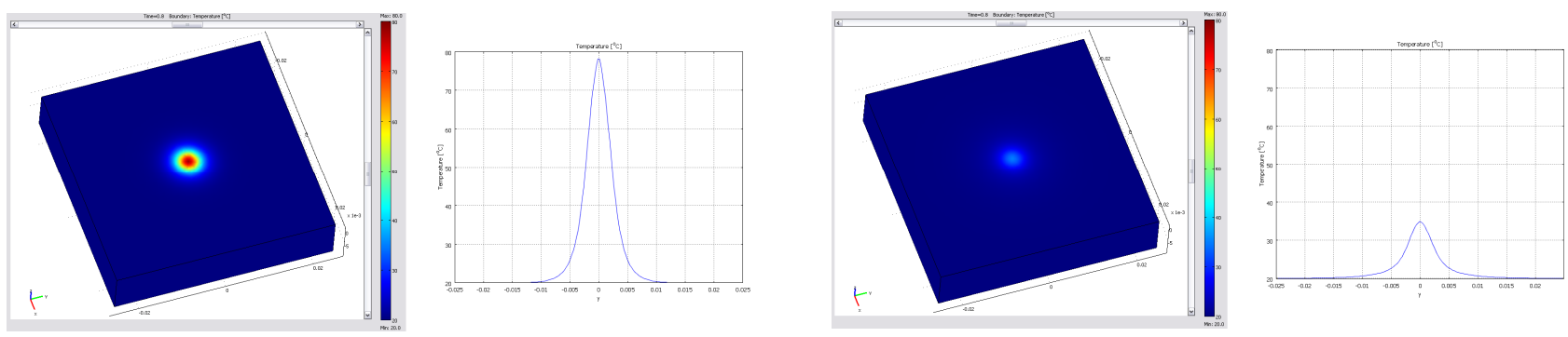

Figure 4: Simulation of laser shot on a low-conductive material (a) and high-conductive material (b) 
The high conductivity of these materials influences also the temporal evolution of the hot spot created by the laser on the surface. On Fig. 5 we present this evolution on an aluminium plate obtained with a $808 \mathrm{~nm}$ laser diode and a incident power of $100 \mathrm{~W}$. At time $0 \mathrm{~s}$, the heating process begins and the hot spot appears. The size of the hot spot grows as the time progresses.

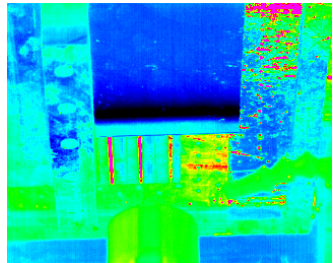

$\mathrm{T}=0 \mathrm{~s}$

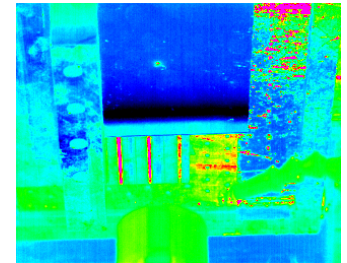

$\mathrm{T}=2,5 \mathrm{~s}$

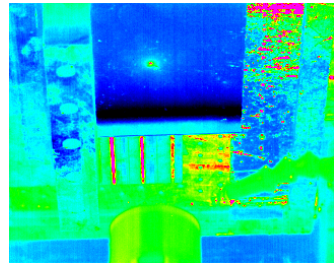

$\mathrm{T}=5 \mathrm{~s}$

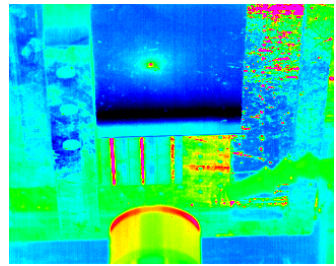

$\mathrm{T}=7,5 \mathrm{~s}$

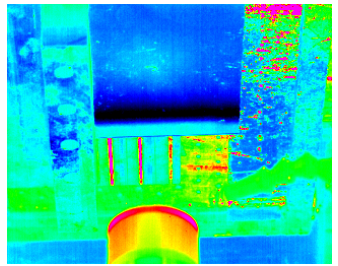

$\mathrm{T}=10,1 \mathrm{~s}$

Figure 5: Temporal evolution of the hot spot

The thermal profile of the hot spot observed by the camera during the heating process is presented on Fig. 6 (a) which is similar to the results obtained by simulation. The impact point of the laser corresponds to the maximum temperature measured by the camera. This maximum is detected using a gaussian convolution mask and the evolution of the computed coordinates, are presented on Fig. 6 (b). The stability of these coordinates is very good and does not depend on the size of the hot spot.
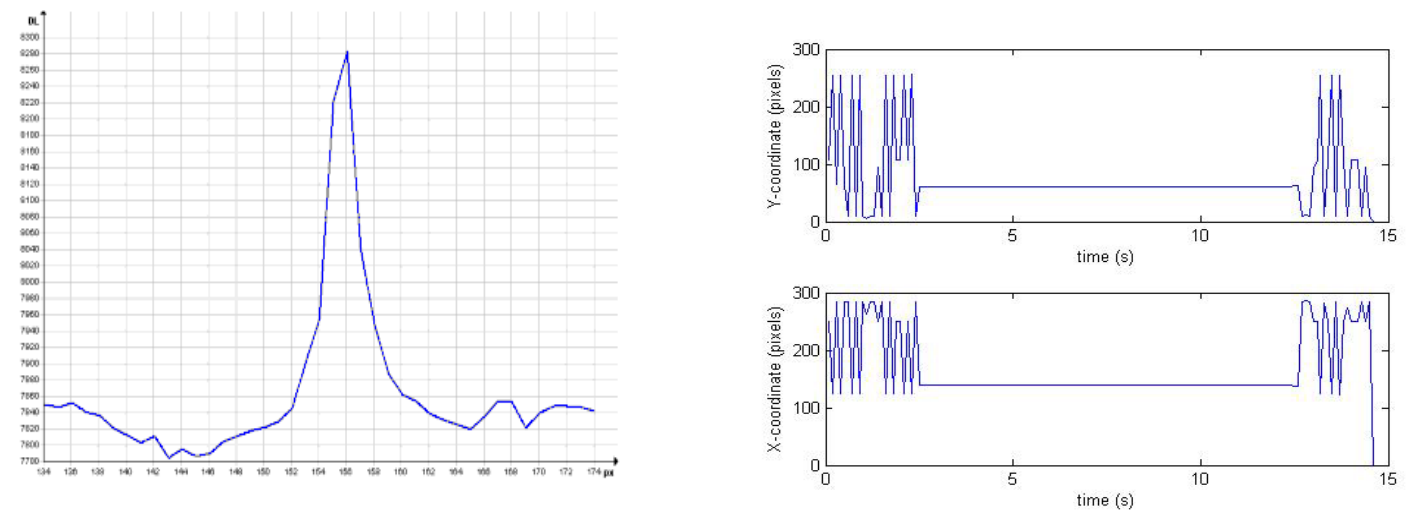

Figure 6: (a) profile of the hot spot along $\mathrm{x}$ axis (b) evolution of the $\mathrm{x}$ and $\mathrm{y}$ coordinates of the maximum temperature point

We can observe on Fig. 5 (for the last image) that the spot disapears instantly when the laser stops. So we can conclude that it is necessary to observe the spot during the heating process. That is why the camera needs to have low sensitivity at the wavelength of the laser, to be protected to possible direct reflections of the laser on the surface. The second remark is that the temperature variation is limited $\left(16^{\circ} \mathrm{C}\right.$ for high-conductive material). So the camera must be able to detect these little variations. According to the Planck's law, a long-wave camera should be able to detect it but the noise of environement should introduce error in the detection of the hot spot (the objects at ambient temperature emit infrared radiation at about $10 \mu \mathrm{m}$ ). That is why we have choosen to realize our experiments using a middle-wave camera (sensible to the band $[3 ; 5.5] \mu \mathrm{m}$ ).

\subsubsection{D Digitization Results}

The experimental setup presented on Fig.7 (a) has been used to realize a test of 3D digitization on a several objects. This setup is composed by an $808 \mathrm{~nm}$ laser diode, a middle-wave infrared sensor ([3-5.5] $\mu \mathrm{m})$. The camera and laser are interdependent with an X-Y moving platform whose displacement accuracy is $10 \mu \mathrm{m}$. The angle between the direction of 
laser radiation and the optical axis of camera is $35^{\circ}$. Since the focal length of lens equals $50 \mathrm{~mm}$, the spatial resolution is $0.345 \mathrm{~mm}$ per pixel.

The whole process (heating, moving and image acquiring) is synchronized with an industrial programmable controller. First, several points at different depths are acquired in order to calibrate the system, by using triangulation calculation. Then, the scanning process can start: for each position of the system, a thermal image is acquired, the maximum of the heated point is computed and the 3D coordinates of the point are determined.

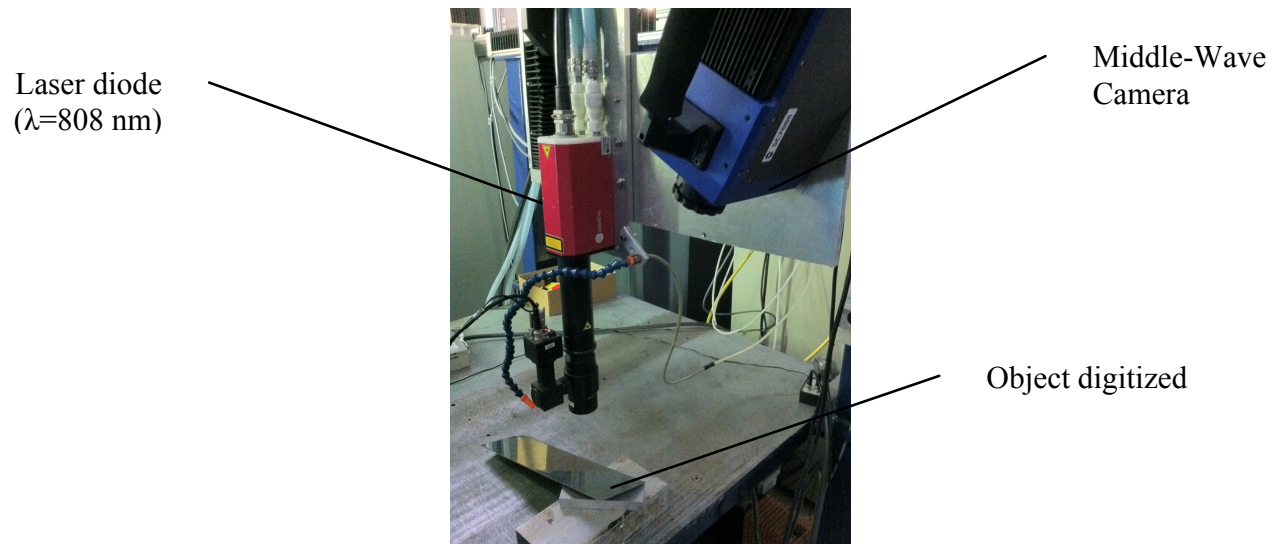

Figure 7: Experimental Setup

The plane presented under the system on figure 7 is made of polished steel. Due to the low roughness of surface, the reflection coefficient is high and the visible reflected rays follow specular direction. The plane is tilted so that we can measure enough difference in the values of 3D coordinates. According to the absorption of this material, the incident power of laser is $15 \mathrm{~W}$. The Scanning process has followed a rectangle grid of 500 points with an increment of $3 \mathrm{~mm}$.

The deviation is computed between each point of the acquired cloud and a perfect plane (see Fig.8). The average deviation is $231 \mu \mathrm{m}$ with a standard deviation of $179 \mu \mathrm{m}$.

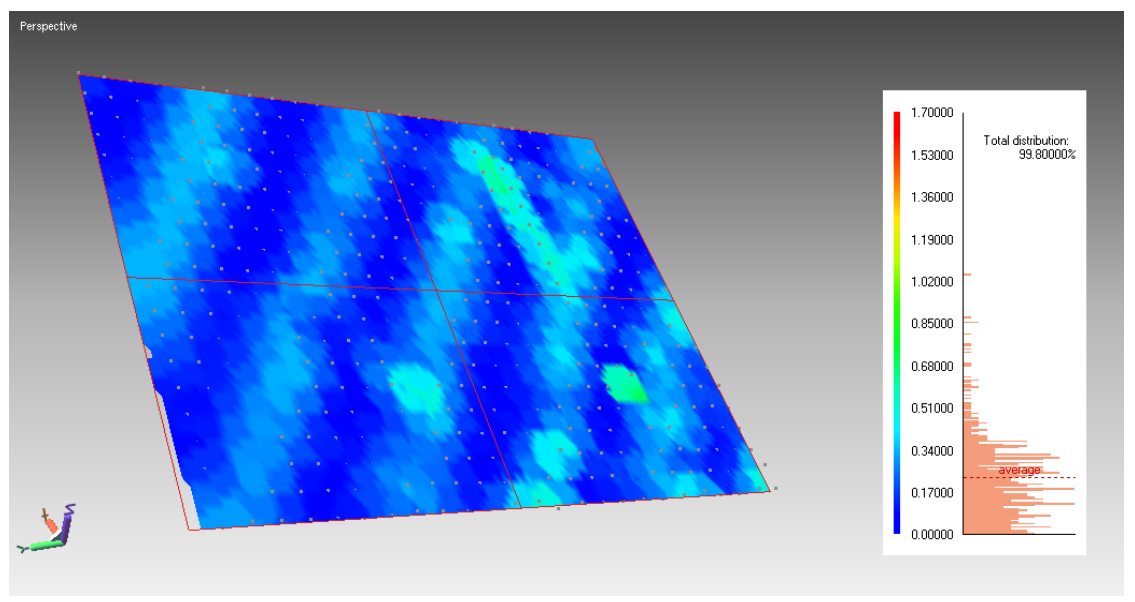

Figure 8: Deviation map between the point cloud acquired on a flat steel object and an ideal plane

We can note a kind of periodic noise following lines which are perpendicular to the visualization direction. These particular partitions are the consequence of the poor spatial resolution. Indeed, the computed Z-coordinate is exactly the same for a given coloured pattern. A way to avoid these different levels is to change the spatial resolution by changing the lens mounted on the camera.

Another digitization has been obtained by scanning an aluminium cylinder with a diameter of $46 \mathrm{~mm}$ shown on fig.9 (a). Because of high thermal conductivity of aluminium, the incident laser power is $18 \mathrm{~W}$ for this test. The scanning resolution is $2.5 \mathrm{~mm}$ and the point cloud contains 400 points. The deviation between this experimental results and a fitted cylinder is reported on fig.9 (b). 


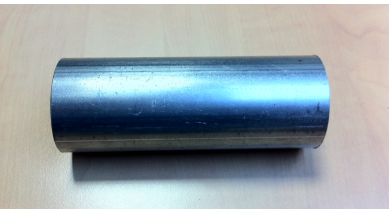

Figure 9: (a) Aluminium cylinder

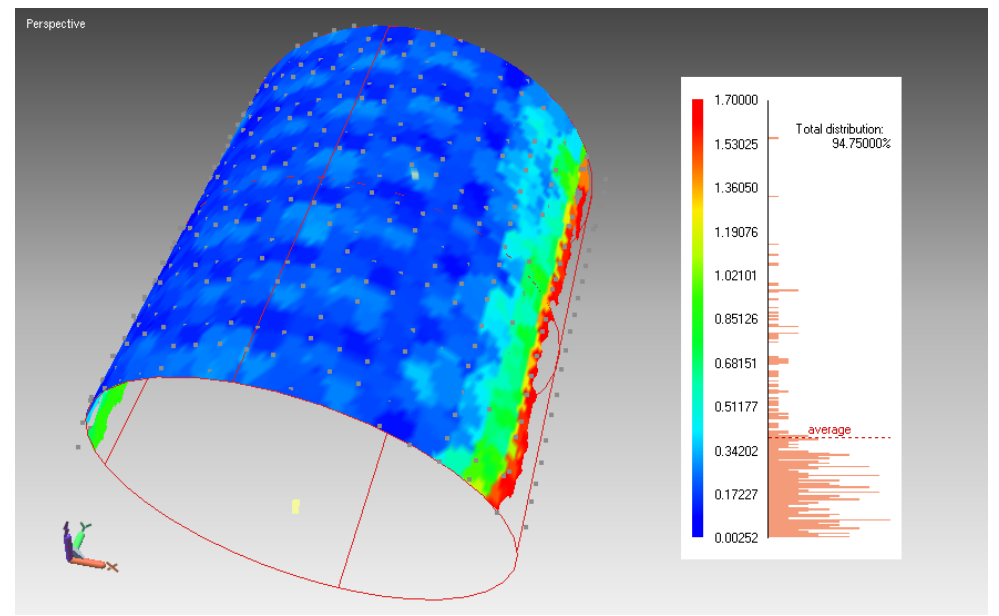

(b) Deviation map between the point cloud acquired on aluminium cylinder and a fitted cylinder

The computed average deviation is $392 \mu \mathrm{m}$ and the standard deviation is $521 \mu \mathrm{m}$. The latter value is rather big because we get a few important errors when the incident ray approach the tangent direction to the cylinder, corresponding to the red area on Fig.9 (b). This error may have several causes: the quality of laser beam, the emissivity dependence on direction, the difficulty to detect the maximum in an elliptic hot spot. However, $76 \%$ of deviation values are below the average value. Furthermore, if we want to reconstruct the whole object, several view point are necessary and can overcome these errors.

Finally, another experiment has been realized on a stainless-steel spoon (object on Fig.10 (a)). The untreated point cloud measured is given on Fig.10 (b). We have acquired 900 points with a regular step of $2.5 \mathrm{~mm}$. The detection accuracy of hot spot seems to be as good on the diffuse background as on the spoon itself.

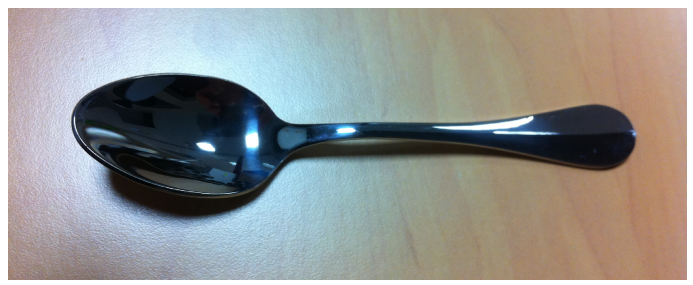

Figure 10: (a) Stainless-steel spoon

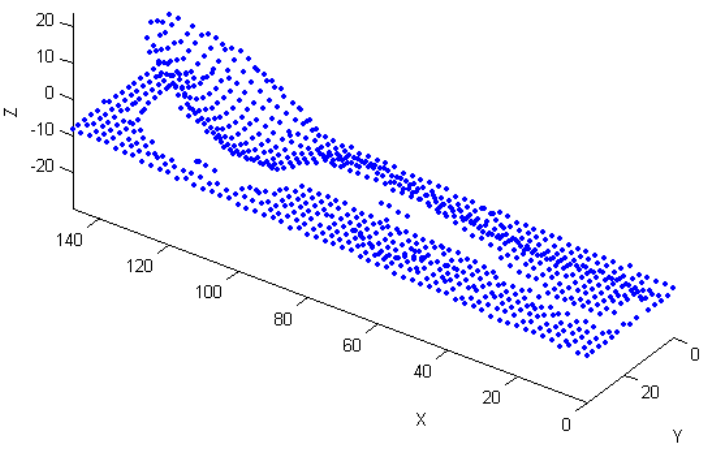

(b) Digitization results (coordinates in $\mathrm{mm}$ ) 


\section{CONCLUSION AND FUTURE WORKS}

We can find in the litterature a lot of approaches dedicated to 3D reconstruction of specular metallic surfaces. Due to specularity, the classical active 3D scanning approach cannot be easily used. In this paper we have presented first experiments obtained using the Scanning From Heating approach, developped initialy for glass objects. Because of differences of the radiative and thermal properties of metals, compared to glass, some adaptations have been choosed (for example the laser source), and tests have been performed to study the influence of the conductivity. Finally, 3D digitization experiments have been conducted. The average digitization error is about $400 \mu \mathrm{m}$ for a cylinder for a measurement distance of $60 \mathrm{~cm}$. The results obtained here are interesting and similar to the results obtained for glasses. So, the future works will be focused on the realisation of an experimental setup with more adapted optic which will definitely improve the performances of the scanner (resolution, speed...). Other metallic materials with different physical properties (copper, brass...) and different shapes will be also tested. For the most part, the perspectives will be to work on the projection of laser light, especially line or 2D-pattern projection.

\section{REFERENCES}

[1] www.kreon3d.com

[2] www.stilsa.com

[3] I. Ihrke, K. N. Kutulakos, H. P. A. Lensch, M. Magnor, and W. Heidrich, "Transparent and Specular Object Reconstruction," Computer Graphics Forum, pp. 1-27 (2010)

[4] M. Tarini, H. P. A. Lensch, M. Goesele, H.-P. Seidel, "3D Acquisition of Mirroring Objects”, Graphical Models 67, 4, pp 233-259 (2005)

[5] S. Nayar, A. Sanderson, L. Weiss, D. Simon, "Specular surface inspection using structured highlight and gaussian images.", IEEE Trans. Robotics and Automation, 6(2), 208-218 (1990)

[6] O. Morel, C. Stolz, F. Meriaudeau, P. Gorria, "Threedimensional inspection of highly-reflective metallic objects by polarization imaging.”, Electronic Imaging Newsletter, 15(2), 4 (2005)

[7] N. Kutulakos, E. Steger, "A Theory of Refractive and Specular 3D Shape by Light-Path Triangulation.”, International Journal of Computer Vision (IJCV),(2007)

[8] G. Eren, O. Aubreton, F. Meriaudeau, L.A. Sanchez Secades, D. Fofi, F. Truchetet, A. Erçil "Scanning From Heating: 3D Shape Estimation of Transparent Objects from Local Surface Heating", Optics Express, Optical Society of America, 17 (14), pp. 11457-11468 (2009)

[9] F. Meriaudeau, L. A. Sanchez Secades, G. Eren, A. Erçil, F. Truchetet, O.Aubreton, D. Fofi,"3D Scanning of NonOpaque Objects by means of Imaging Emitted Structured Infrared Patterns“ IEEE Transactions on Instrumentation \& Measurement (to be published) (2010) 